\title{
Exploring desirable nature futures for National Park Hollandse Duinen
}

\author{
Jan Kuiper ${ }^{1}$, Dianneke van Wijk ${ }^{2}$, Wolf M. Mooij ${ }^{3}$, Roy P. Remme ${ }^{4}$, Garry D. Peterson ${ }^{1}$, \\ Sylvia Karlsson-Vinkhuyzen ${ }^{2}$, Charlotte J. Mooij ${ }^{5}$, Georgette M. Leltz ${ }^{6}$, and Laura M. \\ Pereira $^{1}$ \\ ${ }^{1}$ Stockholm Resilience Centre, Stockholm University \\ ${ }^{2}$ Wageningen University \\ ${ }^{3}$ Netherlands Institute of Ecology (NIOO-KNAW) \\ ${ }^{4}$ Natural Capital Project, Stanford University \\ ${ }^{5}$ Krom Boomssloot, Amsterdam \\ ${ }^{6}$ Nationaal Park Hollandse Duinen
}

August 9, 2021

\begin{abstract}
Achieving global sustainability goals requires most people and societies to fundamentally alter their relationship with nature. New approaches are called for to guide change processes towards sustainable futures that embrace the plurality of people's perspectives on nature. This paper presents a novel approach to exploring desirable futures for nature and people that was developed through an application in National Park Hollandse Duinen in the Netherlands. This new national park is developed bottom-up by a diverse group of actors reshaping their interactions with each other and with nature. Our approach, codesigned with key stakeholders of the national park, engages with a new pluralistic framework for nature values presented by the IPBES task force on scenarios and models to catalyze the development of nature-centered scenarios. We integrated this Nature Futures Framework with the Three Horizons Framework in a participatory workshop process designed to bring people's diverse relationships with nature to the fore, and jointly envision desirable futures and the pathways to get there. An analytical framework is used to analyze and compare the visions and assess their potential contribution to the SDGs. We summarize the results of the application in National Park Hollandse Duinen and reflect on lessons learned. We see much potential for this values-based futures approach to support change processes in various social-ecological contexts toward more sustainable futures for nature and people.
\end{abstract}

\section{Exploring desirable nature futures for National Park Hollandse Duinen}

Jan J. Kuiper ${ }^{1 *}$, Dianneke van Wijk ${ }^{2,3,4}$, Wolf M. Mooij ${ }^{2,4}$, Roy P. Remme ${ }^{5,6}$, Garry D. Peterson ${ }^{1}$, Sylvia Karlsson-Vinkhuyzen ${ }^{7}$, Charlotte J. Mooij ${ }^{8}$, Georgette M. Leltz ${ }^{9}$ \& Laura M. Pereira ${ }^{1,10,11}$

1 Stockholm Resilience Centre, Stockholm University, Stockholm, Sweden; ${ }^{2}$ Department of Aquatic Ecology, Netherlands Institute of Ecology (NIOO-KNAW), Wageningen, The Netherlands; ${ }^{3}$ Water Systems 
and Global Change Group, Wageningen University, The Netherlands; 4 Aquatic Ecology 83 Water Quality Management Group, Wageningen University; ${ }^{5}$ Institute of Environmental Sciences, Leiden University, The Netherlands; ${ }^{6}$ Natural Capital Project, Stanford Woods Institute for the Environment, Stanford University, USA; ${ }^{7}$ Public Administration and Policy Group, Wageningen University, The Netherlands; ${ }^{8}$ Krom Boomssloot, Amsterdam; ${ }^{9}$ National Park Hollandse Duinen, Zoetermeer, The Netherlands; ${ }^{10}$ Copernicus Institute of Sustainable Development, Utrecht University, The Netherlands; ${ }^{11}$ Centre for Complex Systems in Transition, Stellenbosch University, Stellenbosch, South Africa;

* Corresponding author: jan. kuiper@su. se

\begin{abstract}
Achieving global sustainability goals requires most people and societies to fundamentally alter their relationship with nature. New approaches are called for to guide change processes towards sustainable futures that embrace the plurality of people's perspectives on nature. This paper presents a novel approach to exploring desirable futures for nature and people that was developed through an application in National Park Hollandse Duinen in the Netherlands. This new national park is developed bottom-up by a diverse group of actors reshaping their interactions with each other and with nature. Our approach, co-designed with key stakeholders of the national park, engages with a new pluralistic framework for nature values presented by the IPBES task force on scenarios and models to catalyze the development of nature-centered scenarios. We integrated this Nature Futures Framework with the Three Horizons Framework in a participatory workshop process designed to bring people's diverse relationships with nature to the fore, and jointly envision desirable futures and the pathways to get there. An analytical framework is used to analyze and compare the visions and assess their potential contribution to the SDGs. We summarize the results of the application in National Park Hollandse Duinen and reflect on lessons learned. We see much potential for this values-based futures approach to support change processes in various social-ecological contexts toward more sustainable futures for nature and people.
\end{abstract}

\title{
Introduction
}

Humanity has become a dominant force of change up to the planetary scale (Crutzen 2002; Steffen et al. 2015). A dreadful outcome is the wrecking of the Biosphere, despite decades of global conservation efforts. Recent global environmental assessments indicate that wildlife populations have dropped $68 \%$ on average since 1970 (WWF 2020) and one million species are at risk of extinction in the coming decades (IPBES 2019a). The future looks even more grim when considering that humanity is way off track in limiting global warming to $1.5^{\circ} \mathrm{C}$ (UNFCCC 2021). These global assessments univocally stress the need for deep, transformative changes in human societies and economies if internationally agreed-upon sustainability goals are to be achieved (Díaz et al. 2019; Secretariat of the Convention on Biological Diversity 2020). Indeed, supported by the present state of knowledge, human agency in the Anthropocene should be able to "bend the curve" and create sustainable futures for people and nature (Steffen et al. 2011; Bai et al. 2016; Leclère et al. 2020).

The internationally agreed-upon target space for a sustainable development trajectory is presented by the 2030 Agenda of the United Nations through its 17 interlinked Sustainable Development Goals (SDGs) and 169 associated targets - that is, the future we want (UN General Assembly 2012, 2015). Yet, while the Agenda 2030 is forward-looking and aspirational, there is no universal understanding of what a sustainable world for nature and people actually looks like, let alone how to get there. In fact, as people in different places and 
contexts around the world experience, depend on, and relate to nature in many different ways, opening-up for pluralistic perspectives on the futures we want is imperative. What is clear, however, is that most people and societies need to fundamentally rewire their relationships with nature and each other; that there is an urgent need for new ideas, visions and narratives of people-nature relationships to enact transformative change towards just and sustainable futures for life on Earth (Bai et al. 2016; Bennett et al. 2021; Wyborn et al. 2021).

The Intergovernmental Science-Policy Platform on Biodiversity and Ecosystem Services (IPBES) is actively supporting the development of new narratives of desirable nature futures around the world. Building on the findings of the IPBES Thematic Assessment on Scenarios and Models, the IPBES Task Force on Scenarios and Models is mandated to catalyze the development of new nature-centered multi-scale scenarios that are based on positive visions for human relationships with nature (IPBES 2016, 2019b). An important outcome so far is the development of the Nature Futures Framework (NFF). This heuristic tool is used for the collaborative creation of visions and narratives to open up a plurality of perspectives on people-nature relationships while it simultaneously offers a structure for consistency in the development of nature scenarios across multiple scales and diverse contexts (Pereira et al. 2020). Place-based applications of the NFF may i) provide insights into commonalities and divergences across desired visions of nature around the world and their translation into goals and targets, ii) identify scalable policies and actions for achieving desired futures, and iii) develop more diverse sets of indicators to assess progress (Pereira et al. 2020). Currently, there is an articulated need to extend the use of the NFF in real-world case studies to operationalize it globally and to drive an inductive process to develop and refine a family of new nature scenarios (Rosa et al. 2017; IPBES 2019b; Pereira et al. 2020).

At the same time, promising initiatives that seek to transform the way humans interact with nature are already happening 'on the ground'. A notable example where new narratives are being explored is the bottomup development process of National Park Hollandse Duinen (NPHD) in the Netherlands. The ambition of this new National Park is to be a showcase of how people and nature can co-exist (NPHD 2017, 2020a). The surface area of $\sim 450 \mathrm{~km}^{2}$ covers the entire coastline of the province of Zuid Holland, including sea, beaches, dunes, forests, agriculture, urban infrastructure and over a million inhabitants (Veenstra 2020). The geo-morphological foundation was laid 5000 years ago and the interacting forces of nature and humans have shaped this landscape ever since, resulting in exceptional socioeconomic, cultural and ecological values (Van Heeringen and Van der Velde 2017; Neefjes 2018). Current pressures however, including various forms of pollution, urbanization, climate change and sea level rise, are interacting and mounting. A group of local and regional actors recognized that, in the face of the Anthropocene, maintaining the unique landscape qualities and values requires an integrated and collaborative effort that actively engages with the social-ecological complexity and dynamism of the landscape. They initiated a National Park that aims to "reinforce the quality and resilience of both natural and cultural heritage in the landscape of the park by empowering people and organizations to create synergy between natural processes and human activities" (NPHD 2017). Thus, rather than through strict protection, this National Park seeks to safeguard and even enhance biodiversity values by taking an inclusive approach that is rooted in social-ecological systems thinking (Palomo et al. 2014; Cumming et al. 2015; Cumming and Allen 2017). Yet, to achieve its aim and realize its mission, NPHD faces a daunting change process involving numerous actors, interests and desires.

The SDGs, the NFF, and NPHD can be seen as three distinct developments that stem from the same philosophy to reconfigure people-nature interactions towards the mutual benefit and sustenance of all, that is, towards attaining the futures we want. As such, a pertinent question is how these developments may be synergistically combined to purposefully inform and reinforce each other towards that common aim, also speaking to a broader challenge of useful integration of approaches in sustainability research (Lang et al. 2012). In this paper, we present an innovative approach to explore desirable nature futures, consisting of a participatory workshop process and analytical framework. We developed the approach through an application in the NPHD. The workshop process strategically links the NFF to the Three Horizons Framework (Sharpe et al. 2016) to capture diverse perspectives on nature and develop the capacity of stakeholders of NPHD to envision desirable futures and explore transformative changes to get there. The analytical framework is 
developed to analyse the content of the workshop outputs and consists of a thematic analysis and an SDG Target analysis. The overarching aim of this study is twofold: test the NFF at the regional scale and inform the development trajectory of NPHD. The latter includes the potential to develop insights for achieving the SDGs.

We first give a detailed recipe of the workshop process including an introduction of the core frameworks used. We then present the analytical framework and report the results of the approach. In the discussion we reflect on the outcomes and discuss how these outcomes may feed into both the broader development process of the National Park as well as the inductive scenario development process catalyzed by IPBES. We also discuss how to further improve the approach and point to future research needs.

\section{Materials and Methods}

Our approach consisted of two phases. 1) We designed and applied a participatory futures process in Nationaal Park Hollandse Duinen to create a space for stakeholders to explore positive futures for nature based on diverse desirable relationships with nature. Our process strategically integrates the Nature Futures Framework (Pereira et al. 2020), to open-up people's thinking about desired people-nature relations, with the Three Horizons Framework (Sharpe et al. 2016) to focus people's thinking about desired people-nature relations into three distinct time horizons, and how these time horizons might influence each other. 2) We developed and applied an analytical framework that includes a thematic analysis as well as an SDGs target analysis of workshop outputs to better understand the emerging visions and their potential contribution to sustainable development. In the following subsections we further introduce the case study area, present the main frameworks used, provide a step-by-step description of the workshop process and present the analytical framework.

\section{Background}

\section{National Park Hollandse Duinen}

National Park Hollandse Duinen was created in 2016, when drinking water company Dunea brought together 45 parties in the area to participate in the 'Most Beautiful Nature Area of the Netherlands' election (NPHD 2017). This participation - and the election as one of the three most beautiful nature areas by the Dutch public - initiated the development process of one of the first Dutch 'new style' national parks: large areas where high biodiversity, cultural-heritage and socio-economic values co-exist and even reinforce each other (Nationaal Parken Bureau 2018; NPHD 2020a). The ecosystems of NPHD are heavily influenced by humans, if not entirely shaped by them (Neefjes 2018), and yet no less than 6974 species were counted by a citizen science project in the natural areas of the park (https://hollandseduinen. waarneming. nl/5000.php). An example of how nature and people work together is the protection and management of a dune area by Dunea for provisioning of ecosystem services, not least the natural filtration and storage of fresh water to provide 1.3 million residents of the National Park and adjacent areas with tap water. The human-inclusive approach to conservation developed in NPHD builds on a long tradition of integrated landscape approaches in Europe, such as the superseded 'National Landscapes' (Janssen 2009a, b; Janssen and Knippenberg 2012), and shares common grounds with UNESCO Biosphere Reserves (Winkler 2019), IUCN category V 'protected landscape or seascape' (Borrini-Feyerabend et al. 2013), and urban national parks (Roe et al. 2018), such as the London National Park City and Stockholm Royal National City Park. Convened by the National Park, local actors can work together to enhance biodiversity values by strengthening ecological connectivity in the landscape; resolving scale mismatches; enhancing landscape multifunctionality; alleviating existing trade-offs between nature and human well-being; and bolstering the co-benefits of integrated strategies. This may be achieved 
by aligning fragmented management and planning practices; mobilizing investments in green infrastructure and nature-based adaptation; promoting polycentric governance; forging unconventional alliances across sectors; and facilitating experimentation to challenge conventional practices, e.g. through 'living labs'. Twelve concrete projects are presented in the implementation program 2021-2025 (NPHD 2020b)

\section{The Nature Futures Framework}

The Nature Futures Framework is a heuristic tool designed to provide a starting point for creating diverse nature-centered scenarios. The framework engages people's values to create narratives that can be translated into collective action (Pereira et al. 2020). It distinguishes three broad value perspectives (Figure 1):

- Nature for Nature, in which nature has value in and of itself. Nature should maintain its ability to function autonomously, and the preservation of nature's diversity and functions is of primary importance;

- Nature for Society, in which nature is primarily valued for the benefits for humans;

- Nature as Culture, in which humans are perceived as an integral part of nature, where societies, cultures, traditions and faiths are intricately intertwined with nature, and relational values, such as those that reflect cultural identities and ways of life, are dominant.

The Nature Futures Framework draws on other classifications of people-nature relationships. For example, (Mace 2014) describes four main phases in the modern framing of nature conservation: Nature for itself, Nature despite people, Nature for people, People and nature; (Chan et al. 2016) present three key value types underlying nature conservation as instrumental, intrinsic and relational, which are also central to IPBES' guide on multiple values (IPBES 2015). The Nature Futures Framework casts these ideas into three value perspectives that are easy to communicate to a wide audience and positions them in the vertices of a triangular space (Fig 1A). In that way the perspectives draw attention for being different, without judgement of rightness or wrongness, but emphasizing that when taken to the extreme, tradeoffs among these perspectives are inevitable. At the same time, the centrally featured space in between the vertices opens up for the discovery of diversity, relativity and plurality. Indeed, most people will identify with a mix of the three perspectives.

The development of the Nature Futures Framework is driven by IPBES' task force on Scenarios and Models through an iterative process involving strong stakeholder engagement (Pereira et al. 2020). The underlying mandate is to catalyze the development and application of new nature-centered scenarios and models by the broader research community to, ultimately, better inform upcoming assessment studies (IPBES 2019b). The Nature Futures Framework is envisaged to be used flexibly and in different ways, from structuring participatory visioning processes, to quantitative modelling assessments, and ex-post assessments of existing scenarios (IPBES 2021). In this paper we focus on unpacking the Nature Futures Framework as a heuristic device to be used in participatory visioning processes. A key promise of the Nature Futures Framework is to help people identify and articulate their own desired relationship with nature, understand the diversity and plurality of peoples perspectives on nature, and identify and negotiate shared values as fertile grounds for collective actions towards positive futures in which multiple nature values are enhanced (Pereira et al. 2020). In many cases it will be difficult for people to agree on tough decisions about how they engage with nature in the present. It may be easier to jointly deliberate and agree on desired relationships with nature in the future, as a basis for making decisions in the present. This is where the Nature Futures Framework is expected to be useful. 


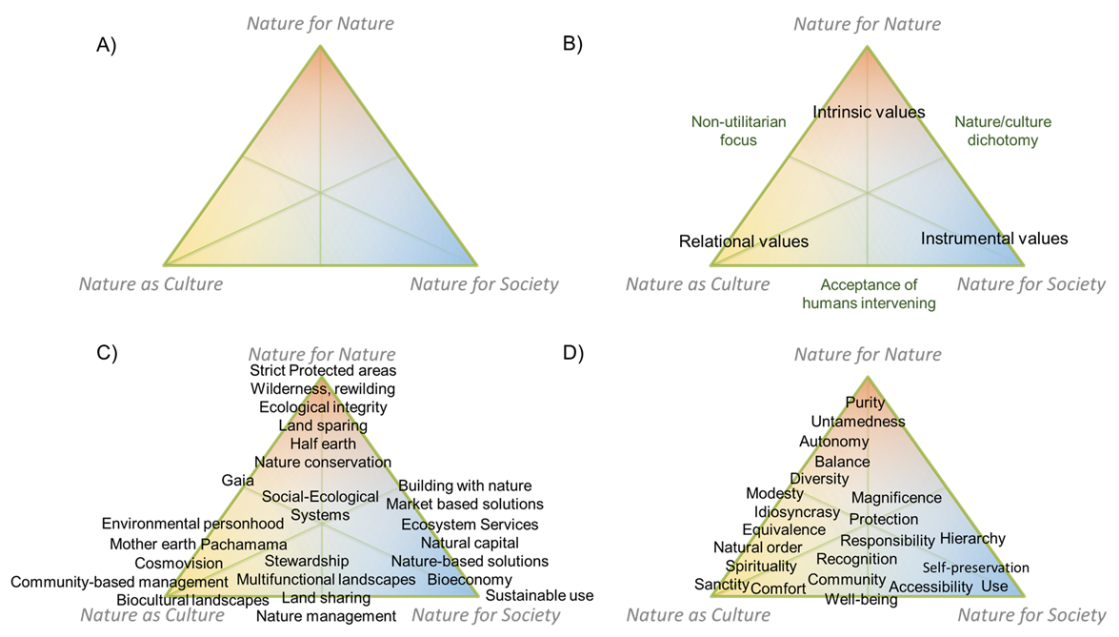

Figure 1. The basic structure of the Nature Futures Framework (a) as during the time of the workshop, as well as three annotated versions (b-d) as presented to the participants to provide additional explanation of the framework to help them understand how it may be interpreted and used. The Nature Futures Framework presents a triangular space (a) with vertices representing three broad perspectives on nature: Nature for Nature (NfN), Nature for Society (NfS) and Nature as Culture ( $\mathrm{NaC}$ ). It accommodates three key value types that are identified by the IPBES guidance on multiple values of nature: relational values, instrumental values and intrinsic values (b). These three values do not map unequivocally to the three perspectives, allowing for their coexistence, but help constitute an interpretation of the altitudes and therewith fundamental differences between the vertices. The altitude through the $\mathrm{NaC}$ vertex can be interpreted as distinguishing people as being an integral part of nature $(\mathrm{NaC})$ from a dichotomy where people see themselves primarily as separate from nature ( $N f S \& N f N)$. The altitude through the $N f N$ vertex may be interpreted as a gradient between the perspective that human intervention is unnatural and undesirable: "Nature can best take care of itself" (NfN) and the perspective that humans contribute to nature, and that management and restoration is principally not a bad thing ( $N a C \& \mathrm{NfS}$ ). The altitude through the NfS vertex differentiates a focus on use (NfS) from a non-instrumental perspective $(\mathrm{NaC}, \mathrm{NfN})$. We note that besides intrinsic value of nature (NfN), the reciprocal relationship of people and nature may have intrinsic value as well ( $\mathrm{NaC}$ ). Furthermore, we showed (c) how examples of popular concepts used in the contemporary debate around nature and biodiversity conservation may be mapped on the Nature Futures Framework, to explain how the Nature Futures Framework may be used to structure discussions on prefered human-nature relationships, and (d) how the Nature Futures Framework may be populated with a broader set of nature values identified by De Argumentenfabriek (2013). Note that the interpretation, presentation and use of the Nature Futures Framework in this paper is independent from IPBES.

\section{The Three Horizons Framework}

The Three Horizons framework is a tool for collaboratively exploring the future. It is a graphical approach where stakeholders are invited to discuss future visions and pathways to achieve them (Curry and Hodgson 2008; Sharpe et al. 2016). It is most applicable in cases of high uncertainty and high agency, in which participants can be creative agents, capable of influencing which future emerges around them. The three horizons present a metaphor to help people consider near, medium, and long term futures. However, beyond just a linear view, the three horizons represent three different ways of relating to the future in the present, thereby welcoming people who hold very different views on the future (e.g. managerial, entrepreneurial, or visionary mindsets). The underlying theory of change looks at how existing dominant patterns and paradigms of the "first horizon" (the world as it is now) could shift to fundamentally new patterns of the 
"third horizon" (the desired future)-through a period of innovation, contestation and transition in the "second horizon", thereby scaffolding discussions about transformative change (Sharpe et al. 2016). The Three Horizons approach has been used in a variety of contexts, including pathways for achieving the Sustainable Development Goals (Aguiar et al. 2020) and the Life Framework of Values that is also used within IPBES (Harmáčková et al. 2021).

\section{The Sustainable Development Goals}

The Sustainable Development Goals (SDGs) of the Agenda 2030 for Sustainable Development are a collection of 17 goals that present "the blueprint to achieve a better and more sustainable future for all". They were adopted by all United Nations Member States in 2015 and should be achieved by 2030. The SDGs are presented as integrated and indivisible, to prevent the occurrence of tradeoffs that hinder progress across the full set of SDGs. The SDGs are operationalized through a set of 169 associated targets (see sdgs.un.org/goals).

\section{The Nature Futures of NPHD Workshop Process}

We applied the participatory futures process during a full day workshop in the dune landscape of the National Park Hollandse Duinen on June 17th 2019. The workshop was collaboratively designed and prepared by a transdisciplinary research team of researchers from diverse backgrounds, including geography, political science, ecology, sustainability science, and the director of the national park. The process was inspired by the workshop process of the Seeds of the Good Anthropocene project as described by Pereira et al. (2017).

\section{Participant selection and preparation}

A group of 23 key stake- and knowledge holders of the National Park participated. They were selected and invited by the director of the National Park and represented a diversity of professional backgrounds (See Appendix A for an overview of categories). During the workshop participants were divided into three groups of approximately 7 people. We aimed to maximize diversity within groups, to create fertile ground for discussion and, ultimately, rich, diverse visions of the future. In the invitation to the workshop, the aims and background of the project were explained, and participants were given a brief overview of the workshop phases. We tried to avoid giving too much detailed information to prevent biasing the participants' views and expectations. The agenda of the workshop as attached to the invitation is presented in Appendix B.

\section{Facilitation}

For each of the three groups there was an organizing researcher who facilitated the process, supported by a note taker. Additionally there was one experienced facilitator that oversaw all groups to jump in when necessary and to ensure that the three groups made similar progress. For the interactive group work we prepared A1-sized sheets with depictions of the basic structures of the Nature Futures Framework and the Three Horizons Framework. Participants captured their input on sticky notes that were placed on these diagrams. The facilitators encouraged discussions but did not push for consensus as to allow for plurality (Turnhout et al. 2020). The goal was to let a rich picture emerge that helps stakeholders understand and respect the diversity of perspectives held by the different stakeholders and which can be further unpacked. Participants did not include their names so that the output became a group product. Throughout the process participants were encouraged to cluster sticky notes thematically to facilitate joint sense making. The process facilitators were supported by a graphic facilitator who created illustrations that captured the outputs of 
the group work throughout the workshop process for all participants to see. The Chatham House Rule was applied to promote a safe environment for creativity and inspiration. The lunch break was combined with a walk through the dune landscape to help participants connect with nature and each other.

\section{Workshop process}

The process consisted of six distinct phases. The first phase focused on introductions and 'setting the scene' where each participant reflected on their personal relationship with nature. After the first phase the participants split up into their groups. The second phase focused on unpacking and populating the Nature Futures Framework. During the third, fourth and fifth phase we focused on the Three Horizons for visioning and pathway exploration. During the sixth and final phase the groups presented their work and insights to each other followed by a plenary reflection and discussion for joint sense making and identifying possible follow-up steps.

\section{Phase 1: Introductions and setting the scene}

The workshop started with an icebreaker exercise that was designed to inspire. In the invitation for the workshop, participants were asked to bring a picture or other type of object that captures or represents a strong personal relationship with nature. During the introductions, participants were asked to introduce themselves based on the explanation of what they brought. The goal was to nurture a positive and natureoriented mindset among participants and already get a sense of the diversity of relationships held by different people. Also, avoiding introductions based on which organization people represent may help build a safe environment for creativity and out-of-the box thinking. After the introductions the participants split into three parallel groups.

\section{Phase 2: Annotating and unpacking the Nature Futures Framework}

Each of the participants was asked to position their picture or object on the triangular space of the Nature Futures Framework and explain to the other group members why they chose the respective place in the triangle. Populating and discussing the triangular space aimed to open-up a plurality of perspectives and create a rich value foundation for the visioning. The facilitators asked the following questions: Why is nature in NPHD important for you? Where in the triangle do you belong, identify yourself with? After everyone had their turn, participants were asked to place additional perspectives using sticky notes, either representing themselves or the organisation they represent. We asked: Why is nature important for the people you represent? Which groups of people may identify themselves with which parts of the triangle? Subsequently, the groups reflected on which areas of the triangle were populated and which areas were still open to check which perspectives might be missing, to discuss multiple values for nature. We asked: Is the entire triangle populated? What are shared and connecting values? Where are the gaps? Are there perspectives missing?

\section{Phase 3: Third Horizon}

The third phase focused on the third horizon, that is, a desirable future (a system we want to transform to). The goal was to imagine elements of positive futures for people and nature in NPHD (Fig 3A). The facilitators asked the participants: What does a desirable future of NPHD look like, if we project our (shared) nature values onto the future? To ground the envisioned futures in the present world, we asked: What are pockets of the future in the present, or 'seeds' that have the potential to sprout and grow a desirable future. After several rounds of adding elements, we used a prompt to help participants synthesize and cast their diverse imaginations into sets of keywords in the form of newspaper headlines. We asked: Imagine and formulate a 
future newspaper headline about National Park Hollandse Duinen. What does it say? The headlines provided useful input for the graphic facilitator.

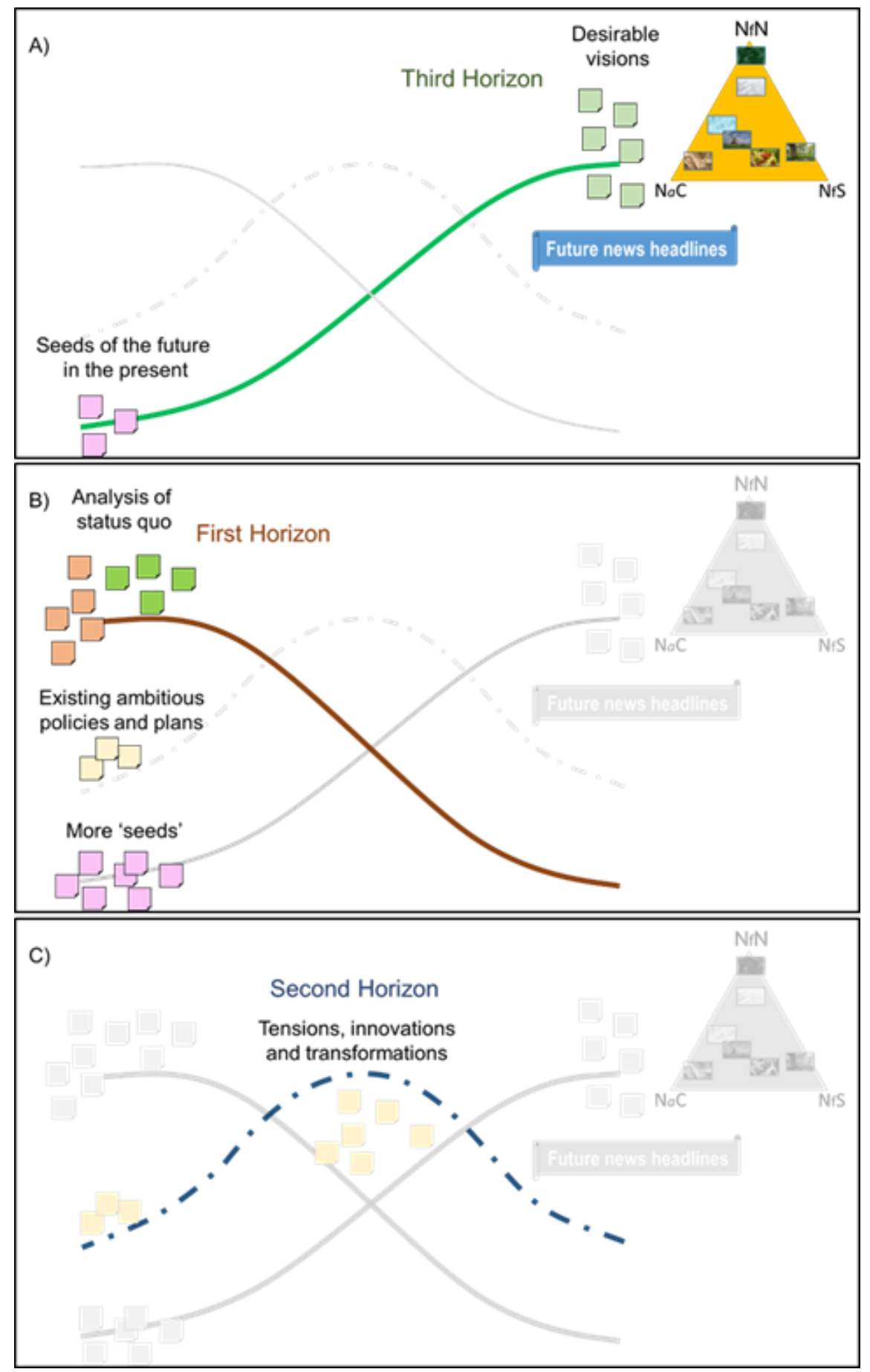

Figure 2. A depiction of how three phases of the workshop focused on the Three Horizons. a) Phase 3 focused on the Third Horizon. b) Phase 4 focused on the First Horizon. c) Phase 5 focused on the Second Horizon. On the $x$-axis is time, without units, and on the y-axis is 'dominant patterns', without units. 


\section{Phase 4: First Horizon}

The fourth phase focused on an assessment of the current system, that is, the first horizon. What are things people cherish and want to maintain into the future, what needs to grow, and what needs to be phased out (Figure 3B). Questions asked to the groups were: What in the current area of NPHD contributes to, impedes, and needs to develop to create desirable futures for NPHD? Different colors of sticky notes were used to differentiate desirable features from undesirable features. New and promising policies and plans that have come into effect but are too new to have had any effect are mapped onto the middle of the first horizon, as a lead-up to the second horizon. Additionally, we encouraged participants to think of more seeds in the present, and agree on three seeds that are considered particularly promising for growing the third horizon, which were captured by the graphic facilitator.

\section{Phase 5: Second Horizon}

The fifth phase focused on the transitional space and thinking about enabling actions, that is, the second horizon (Figure 2C). Questions asked to the groups were: What needs to happen to transition from the present towards the desired futures? Which innovations are going to be game changers in the near future and play a role in the transitions? Where will the main tensions and contestations arise? Can we identify synergies between nature values, innovations and seeds? The emerging discussion then naturally converged into a few key talking points. We asked the groups to come up with a name of their group that represented these defining issues, as well as three key words.

\section{Phase 6: Group Presentations and Plenary reflections}

During the final phase the groups presented their main outcomes to each other, using their sheets and the artwork of the graphic facilitator. Discussions and reflections continued in plenary using a semi-free format. The questions we used to guide the discussion were: What did the participants learn? What are lessons for NPHD? What will the participants take back to their organizations? What are follow-up steps? The discussion was moderated by the director of the National Park.

\section{Analytical Framework}

The analytical framework was applied to the co-produced group outputs for the third horizon, which sketch a coarse vision of a desirable future of the National Park. The framework consists of two parts, a thematic analysis and an SDG Target analysis.

\section{Thematic analysis}

Developing a thematic structure to present the envisioned futures for NPHD in the third horizon helps with ex-post sense-making of the content produced within subgroups as well as comparison across subgroups. Such structured comparison facilitates identification of commonalities as well as differences and divergences, which may point to consensus and disagreement across the stakeholders about the future of National Park Hollandse Duinen. Additionally, it facilitates cross-case comparison with other bottom-up scenario processes using a similar structure and the uptake of the content into the inductive scenario development process of new global nature scenarios for IPBES based on case studies from across the world (Pereira et al. 2020). 
After the workshop we entered transcripts of the sticky notes from the annotated participatory diagrams into a spreadsheet database. Then, for each of the groups, we organized the entries into thematic categories. To do so, we first checked for clusters of sticky notes as formed by the participants themselves during the workshop process. Notes from the subgroup discussions served as a guide to interpretation of post-it transcripts and emergent clusters. Additionally, we looked at thematic categories that emerged from a pilot application of the Nature Futures Framework in Brazil (Rana et al. 2020) and a narrative building workshop by the IPBES Task Force on Scenarios and Models (PBL 2020) and adopted relevant categories to complement or merge with the previously identified categories. This was to start to develop some level of consistency between various case studies that use the Nature Futures framework. It is envisaged that with each iteration, a final group of categories that are relevant across different contexts and cases will emerge.

\section{SDG Target analysis}

The SDGs provide humanity with a target space for sustainable development. Thus, arguably, the SDG targets represent the internationally agreed third Horizon of the world. As such, they may be compared with the third horizon for NPHD to assess how the envisioned futures of NPHD may help achieve the international vision for sustainable development as portrayed by SDGs, and vice versa.

\section{Content analysis}

The SDG Target analysis started with an inspection of each of the 169 SDG Targets. Two researchers assessed which of the targets are relevant for National Park Hollandse Duinen, first without reference to the workshop outputs. Filtering out all the SDG Targets that are clearly not relevant, at least according to the understanding of the researchers, presents a potential SDG space against which the results of the outputs of the workshop process may be compared. Next, following Jiménez-Aceituno et al. (2020), we used content analysis to identify the SDGs and related targets addressed by the sticky notes that shaped the third horizons generated by the workshop process. The sticky notes of the third horizon provided the sampling units, the expressions on the sticky notes provided the data collection units, and the SDG targets were the units of analysis. For each of the sticky notes we checked whether they met each one of the 169 SDG targets in an iterative process of coding and re-examining. Additionally, for each of the sticky notes, we selected one Goal that was most relevant (see Appendix C for an example). We analyzed the data collection units in the original language (Dutch) to prevent meaning going lost in translation. The notes from the subgroup discussions served as a guide to the interpretation of the data collection units. Yet, here we acknowledge that the information provided by the sticky notes is diverse and, inherently to sticky notes, limited. Some ideas and preferences for the future of NPHD clearly speak to one or several SDG targets. In other cases, however, some interpretation by the researchers was unavoidable, for example when expressions were formulated ambiguously or so broad that they touched upon various SDG targets, albeit not very directly. In those cases, the researchers discussed their interpretations until consensus was reached. In general, because the workshop outputs were supposed to provide more of a rich picture than a clearly articulated vision, the researchers were inclusive in their judgement. Also, akin to (Jiménez-Aceituno et al. 2020), the SDG targets were, in some cases, adapted to be relevant for the analysis of this workshop process. For example, when the year 2020 was mentioned as part of the target description we used 2030 instead.

\section{Descriptive analysis}

We used descriptive statistics to explore which SDGs, and how many of the SDG targets were addressed by the sticky notes that shaped the third horizon for NPHD. These targets may be used to discuss the potential of NPHD to contribute to the Agenda 2030 if the visions would give direction to the development process. Subsequently, we identified which of the SDG targets that, a-priori, were considered by the researchers to 
correspond with the mission of NPHD did not appear in the broad visions for NPHD produced during the workshop process. These targets may be discussed as unrecognized potential of NPHD to contribute to the Agenda 2030.

\section{Results}

Our approach produced two types of outcomes. First, we report on the participatory workshop process in NPHD that combined the NFF and the Three Horizons Framework. Second, we present results from the thematic analysis and the SDG Target analysis.

\section{The Nature Futures of NPHD Workshop Process}

\section{Surfacing perspectives on relationships with nature}

Stakeholders expressed diverse relationships with nature during step 1 and 2 of the workshop process. In all groups the triangular spaces of the Nature Futures Framework were abundantly populated by photos, objects and descriptions that express people's relationships with nature. These items, across all groups 81 in total, were mapped all over the triangular framework spaces (Fig. 3). Most of the items that were placed in the corners of the triangle were not positioned in the very extremes. Not all contributions could be translated into text, but examples from the written expressions were: 'Natural dynamics' and 'Cycle of life' for the Nature for Nature perspective; 'Food production' and 'Recreation' for the Nature for Society perspective, and 'Identity' and 'Cultural landscape heritage' for the Nature as Culture perspective. Examples from the center space were: 'Provides a memory' and 'Puts human existence into perspective'. Not every participant immediately understood the Nature as Culture value perspective, and how it differed from Nature for Society . However, confusions were resolved quickly after discussing a few different examples. Eventually, relatively few expressions were attributed to the Nature for Nature perspective (Fig. 3).

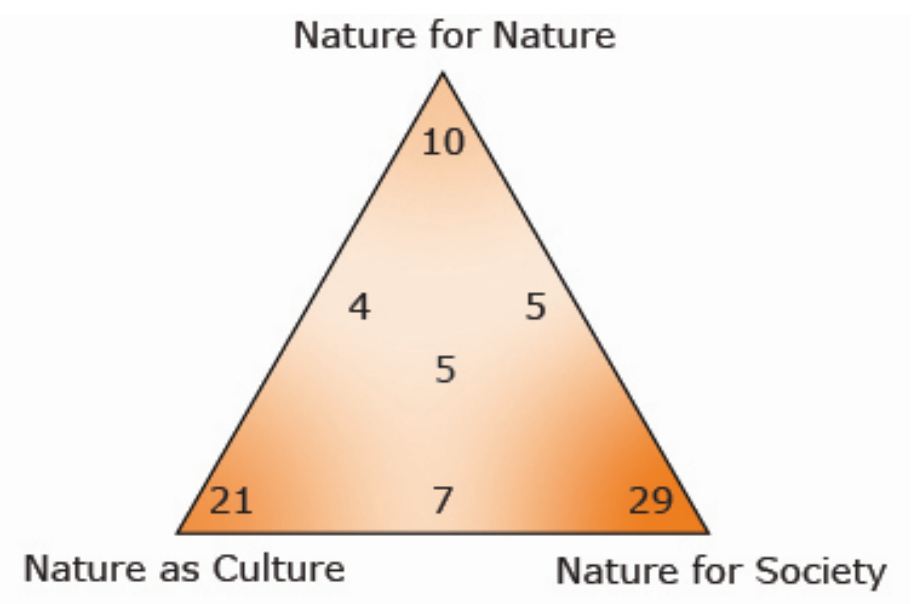

Figure 3 Heat map showing the distribution of expressions across the triangular space of the nature futures framework, aggregated for the three groups. Note that in this figure we organized the expressions of the participants into 7 locations for communication purposes, fully aware that this goes against the idea of the NFF to embrace diversity and plurality. 


\section{Group visioning process}

Rooted in the elicitation and discussion of values associated with nature, phase 3,4 and 5 produced rich discussion about desirable futures for NPHD and the transitions needed to get there. Table 1 summarizes the main features of the three groups in which these discussions are reflected. We present the inputs for the third horizon in Table 2, and first horizon in Appendix D Table A1.

Table 1 Names, sticky notes on the Three Horizons diagram, keywords and headlines of the three subgroups. Group name

$\mathrm{Nr}$ of sticky notes

Key words

Third horizon newspaper headlines

While all the groups discussed each of the three time horizons, the groups differed in which horizon was explored the most. 'How Green is Red?' and 'Our park Hollandse Duinen' focused mostly on discussing the future of NPHD in the third horizon, while 'The Bridge Builders' left the third horizon more open but spent relatively more time unpacking the first Horizon to identify what needs to remain and what needs to change. The second horizon was least explored. The second horizon was also used strategically to park major trade-offs or taboo's that need to be addressed at some point but could not be solved during the workshop discussion. Examples are intensive agriculture, what is fair distribution and allocation of scarce space, and whether or not the national park should engage with behavioral change.

\section{Plenary discussion and synthesis}

The plenary discussion during the final step of the process highlighted several cross-cutting factors. Multiple participants mentioned that the large scale of NPHD with multiple functions offers opportunities to collaborate on shared goals, but more effort needs to go into identifying and taking away fundamental barriers. The participants articulated the need to identify a shared set of key values and principles to self-organize their collective efforts, like "a swarm of starlings", or the "DNA of NPHD", without compromising on the richness and diversity of nature values that can be found in the National Park. A pertinent follow-up question that was brought up is how to monitor progress and success. At the end of the workshop we asked people what they would like for a follow-up workshop. Some participants expressed the desire to have more time to continue unfinished discussions or to talk and work more towards concrete actions. For example, someone said: "now we need to get more concrete; now we need maps and start drawing".

\section{Thematic analysis}

We identified 9 thematic categories to present the output generated during the exploration of the third horizon (Table 2). These categories emerged through comparing and integrating clusters made by participants with the thematic categories presented by other applications of the NFF (PBL 2020; Rana et al. 2020).

Table 2 Output on the third horizon for the three groups organized around themes. We merged some duplicants and clarifie Group / Themes

Spatial planning; Landscape, urban, infrastructure design.

Governance, Policy, Regulations

Agriculture and production from land. 
Economy, trade and transport

Technology and Nature Based Solutions

Energy

Biodiversity and nature management

Livability, health, environment and well-being

Social structure, community participation, behavior, norms, education, awareness

Culture and heritage.

The structuring shows that the produced outputs for the third horizon cover various fundamental features of societies and social-ecological systems, serving as ingredients for an integrative narrative of a desirable vision of the future for NPHD. The structuring also reveals plurality within the groups, as the emerging narratives embed a mix of people-nature relationships. Some apparent trade-offs occur within the groups. For example, in 'Green is Red', the landscape supports businesses and food production but also natural dynamics. Various consistencies across the groups can be found, such as the focus on health, the contribution to the local economy and the presence of agriculture. No striking divergences occur across the groups, though it must be noted here that such comparison is limited by the amount of content, especially for the 'The bridge builders' who focused more on unpacking the first horizon (Appendix D Table A1).

\section{SDG Target analysis}

Assigning one most relevant SDG to each of the sticky notes of the third horizon shows that, across all groups, three goals stand out: Goal 11 (Sustainable cities and communities; 21\% of the sampling units), Goal 15 (Life on land; 18\%) and Goal 8 (Decent work and economic growth; 15\%). All but three SDGs were represented: Goal 1 (No Poverty), Goal 5 (Gender Equality), and Goal 10 (Reducing Inequality).

Coding the 72 sticky notes for the SDG targets resulted in 236 scores. We found that 56 of the 196 SDG targets were represented at least once (Fig. 4). There are 7 targets that we observed in our sample at least 10 times: Target 8.4 (Improve resource efficiency and endeavour to decouple economic growth from environmental degradation); Target 11.4 (Protect and safeguard the world's cultural and natural heritage); Target 11.7 (Safe and inclusive green and public spaces); Target 11.a (Positive economic, social and environmental links between urban, peri-urban and rural areas); Target 15.1 (Conservation, restoration and sustainable use of terrestrial and inland freshwater ecosystems and their services); Target 15.5 (Reduce degradation of natural habitats, halt the loss of biodiversity, protect and prevent the extinction of threatened species); Target 15.9 (Integrate ecosystems and biodiversity values into national and local planning, development strategies, and accounts). 


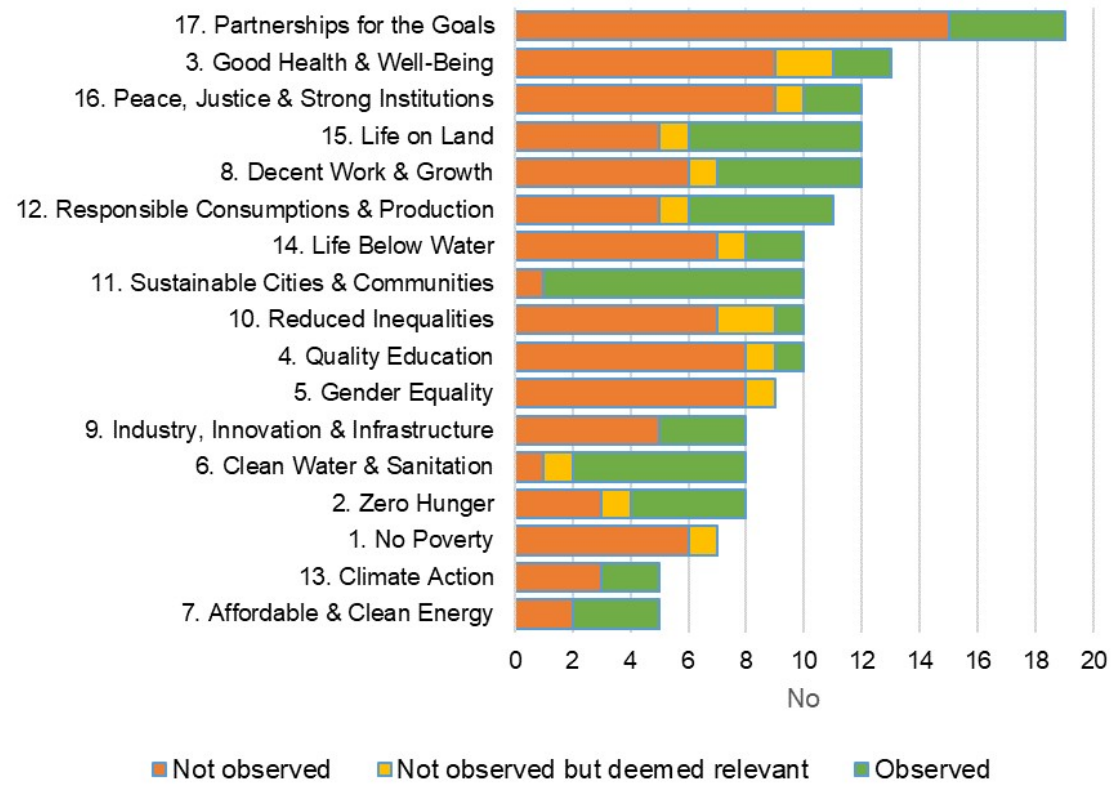

Figure 4 Number of targets under a specific SDG, and the distribution of targets appearing in our sample (Observed), the number of targets that do not appear in our sample (Not observed), and the targets that do not occur but were identified as potentially relevant for NPHD during an a-priori assessment (Not observed but deemed relevant). For example, SDG 17 has 19 targets. 4 of these targets appear in our sample, while 15 targets are not represented.

The distribution of all the scored targets across our sample confirms the pattern at the SDG level that Goal 11, 15 and 8 stand out, and that Goal 1,5 and 10 are not represented (Fig. 5). 


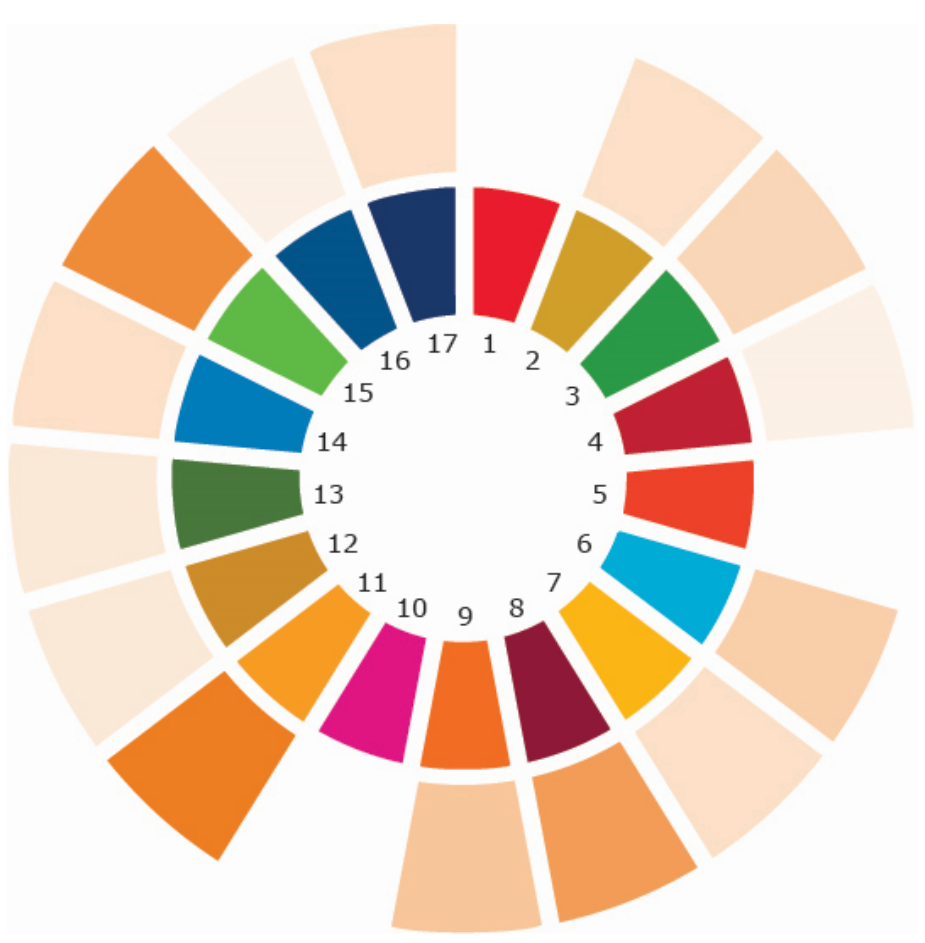

Figure 5 Representation of the SDGs based on frequency of observed targets appearing in our sample. Goal 11 (Sustainable cities and communities), Goal 15 (Life on land) and Goal 8 (Decent work and economic growth) are most represented. Goal 1 (No Poverty), Goal 5 (Gender Equality), and Goal 10 (Reducing Inequality) are not represented.

We identified only a few SDG targets that were considered relevant for NPHD during the a-priori assessment but which were not explicitly brought up by the participants during the workshop (Fig. 4). These are targets: $1.5 ; 2.1 ; 3.3 ; 3 . \mathrm{D} ; 4 . \mathrm{a} ; 5.5 ; 6 . \mathrm{a} ; 8.5 ; 10.3 ; 10.7 ; 12.6 ; 14.1 ; 15.7 ; 16$. b.

\section{Discussion}

Working on sustainable development of the biosphere, whether it is towards desired futures of local environments or achieving international goals, requires action-oriented approaches that are pluralistic and integrated (Bai et al. 2016; Jacobs et al. 2020; Caniglia et al. 2021). We present a novel approach to exploring desirable nature futures and what it takes to get there that we applied in National Park Hollandse Duinen. Our aim was to test the NFF at the regional scale and inform the development trajectory of NPHD. Here, we reflect on what we learned by applying the approach and present pointers to future research.

\section{Reflections on the approach}

As people's decisions and actions are underpinned by their values, the role of values in sustainability transformation is increasingly discussed (Bieling et al. 2020), whereby plural valuation is recognized as key for inclusive and fair decision making (Muradian and Pascual 2018; Jacobs et al. 2020; Hensler et al. 2021). 
Yet approaches that show how different values, and their combinations, drive the unfolding of the future remain scarce (Harmáčková et al. 2021). The NFF proved an easy to use tool that is effective for eliciting and discussing diverse and plural value perspectives of nature as a basis for a place-based visioning process. As one of the first field tests of the NFF, the application in NPHD showed that all three value perspectives, includingNature as Culture, can resonate in a densely populated area in northwestern Europe.

The process in NPHD yielded rich discussions that serve as a source of inspiration for stakeholders. Tellingly, the three group names embody and hence point to important strategies for dealing with identified challenges, that is, a hard coupling between housing development and nature development (How Green is Red?), making connections, physical and relational, for new partnerships (The Bridge Builder), and strengthening local identity as a leverage point for collective action (Our Park Hollandse Duinen). The process helped participants discuss how not everything is possible, but a lot might be, especially when underpinned by a joint sense of what the overall direction should be. Collaboratively created visions serve as a boundary objective to have constructive conversations about what that direction should be (van Rooij et al. 2021). Such visions can, and even should, be pluralistic (McPhearson et al. 2016); they do not have to be fully shared among actors to provide a target space for collaboration. Importantly, the participants identified a critical need of a shared set of key values and principles, the "DNA of NPHD", to structure a boundary process towards the desirable futures for NPHD (Fig. 6), to fly as a "flock of starlings". To a large extent the pluralistic vision and shared principles are already formed by the national park partners, as presented the official ambition document (NPHD 2017) and landscape strategy (Veenstra 2020), following extensive stakeholder engagement. Yet, in support of the first working program of NPHD 2021-2025 (NPHD 2020b), these can be further evolved, enriched and operationalized.

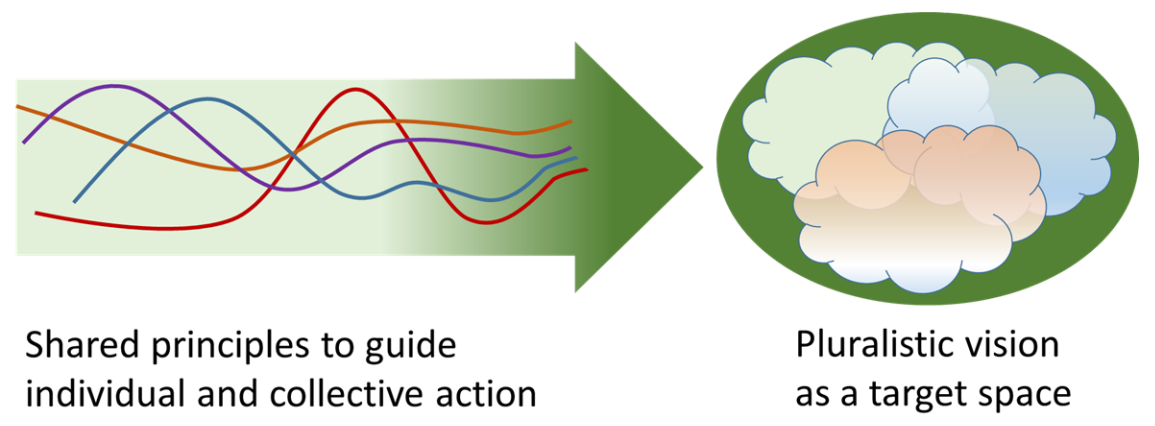

Figure 6 Conceptual figure depicting how a loosely defined collective vision can act as a boundary objective for a boundary process guiding individual and collective actions based on a set of shared principles.

Indeed, the approach aligned well with the broader development process of NPHD. As such, the process did not initiate a structural break in the development trajectory of NPHD. Rather it supported the existing process, for which it was recognized as a useful tool by the director of NPHD, who was involved in co-design of this study and is an author on this paper. Starting the process with surfacing and reflecting on people's diverse relationships with nature, facilitated by the NFF, was something that resonated. It inspired a more reflexive approach in subsequent engagement processes (Schultz et al. 2018; Horcea-Milcu et al. 2019); How are people entering the process; what values do they hold and bring in? So far that was a bit underexposed in the broader development process of NPHD.

Another aspect of the process that resonated was the exploration of the three time horizons. That thinking fitted-in well with a broader but somewhat ad-hoc iterative process of dreaming big and reflecting on the present by National Park actors, and helped to emphasize long-term thinking during development of NPHD's landscape strategy (Veenstra 2020). More generally, what worked well was the clear structure and stepwise design of the process, through the six phases, that still allowed for flexibility in how it was applied. The success of visioning processes often depends on who participates. Indeed, not everyone feels comfortable 
with dreaming about a radically different future. Useful therefore is how the Three Horizons Framework promotes inclusivity as it provides flexibility to switch between time horizons depending on the emerging group dynamics. This was reflected by the dynamics of the three groups in this workshop: each completed the six phases of the process, but focused on different parts (Table 1). Furthermore, what was appreciated was that the workshop process based on the NFF and the Three Horizons is rather different from traditional workshops. As such, it offered the actors involved in the co-design of the process a reflection on alternative tools and methods for informing change processes, and enlarged their toolbox of available workshop methods.

\section{Contributing to the Agenda 2030}

The SDG Target analysis shows how development of NPHD towards the envisioned futures would result in progress for almost all of the SDGs. In particular there appears to be a large potential for NPHD to contribute to Goals 8, 11, and 15. Our analysis also uncovered several SDG targets that are deemed relevant for NPHD but which were not brought up by the participants during the workshop. These targets may indicate unrecognized potential for NPHD to contribute to sustainable development. For example, one topic that was clearly underexposed is equity (targets 5.5, 16.b, 10.3, 10.7). There is also relatively little attention for the contribution of NPHD to public health (targets 3.3, 3.D), though it must be noted that the workshop process took place a few months before the COVID-19 pandemic hit. Recent increased attention to nature-health relationships is likely to have shifted this focus (Kleinschroth and Kowarik 2020).

It is important to point out the limitations of the SDG analysis as applied in this study. The sticky notes are not very suitable as sampling units as they contain limited and diverse information. In response, the researchers took an inclusive approach to coding the sticky notes. It is likely that more specific ideas for the future of NPHD have scored fewer targets than broad or ambiguously formulated ideas indirectly touching on various targets. It is therefore important to focus on the more generic patterns that emerge from this analysis, such as the three goals that clearly stand out and the most frequently appearing targets. Indeed, the SDG Target analysis is not intended to provide hard evidence, rather as a starting point for critical reflections on which aspects of sustainability are to be considered and prioritized by NPHD. Even so, an additional step of Jiménez-Aceituno et al. (2020) that we have not done here but which can still provide interesting insights is an analysis of interactions between the SDGs through the elements of the visions. This may help understand how progress towards a specific target may be leveraged to attain various aspects of a desirable future for NPHD.

Heinrup and Schultz (2017) described UNESCO Biosphere Reserves in Sweden as arenas for implementing the Agenda 2030, distilling five key functions: they serve as platforms for collaboration; connect actors vertically and horizontally, maintain healthy ecosystems, promote learning and awareness raising, and integrate the SDGs. As a close relative of Biosphere Reserves, NPHD too can be an arena for implementation of the 2030 Agenda. Yet, to date, the SDGs have not played a significant role in the development process of NPHD, nor more generally in Dutch nature conservation and landscape governance. However there are actors in the region who are actively engaging with SDGs as part of their operations. As such, NPHD may strategically employ the SDGs as a tool to link with specific actors. Similarly, adopting the SDGs may help to better portray the international context of the National Park. The insights gained through the SDG target analysis about which Goals and Targets are relevant are expected to be useful here.

Besides understanding how NPHD may contribute to achieving the SDGs, the visions for NPHD, and NFFinspired development processes more generally, may also provide valuable insights into what aspects of sustainable development are currently missing from the SDGs. We did not do an NFF analysis of the SDGs but close inspection of the SDG targets informed us that there is much focus on Nature for People and a bit on Nature for Nature but very little on Nature as Culture value perspectives. We note for example that landscapes are not represented in the SDGs, let alone biocultural landscapes (Chakroun and Droz 2020; Hanspach et al. 2020). Zheng et al. (2021) recently highlighted a general underappreciation of culture in the 
Agenda 2030. We point to a critical interrogation of the SDGs using the NFF as important future research.

\section{How the process can be further developed}

The 1-day workshop process, whilst a useful activity for the stakeholders and as a case study to explore how the NFF could be operationalized in a local level case study, also had its limitations. For a fully immersive futuring process, it is advisable to bring people together for a couple of days at a time so that they can really engage fully with the process, unpack potential inconsistencies and work through potential conflicts. This workshop process was developed from a longer Manoa mash-up method approach that was initially established as a 3-4 day workshop (Pereira et al. 2017; Raudsepp-Hearne et al. 2020). A potential next step could therefore be to consolidate the visions that emerged during the workshop in NPHD into more integrative and coherent narratives through a longer process whereby a full Manao mash-up method is employed. Steps for such extended narrative development could build from the newspaper headlines in this paper (Table 1) and use either the VERGE framework to ask participants to describe certain aspects of the future world, such as what is created/what is destroyed/what is consumed (Lum 2015) or take a more science-fiction prototyping approach whereby a narrative is developed around a core character in this future world (Merrie et al. 2017). The latter has informed the development process for illustrative narratives of future worlds using the NFF (PBL 2020). Another aspect could be to get more creative with the visions so that they are able to draw on people's emotional attachment to the national park (Pereira et al. 2019). Graphic facilitation helped participants to visualize their discussions, but more engaged artistic experiences such as through theatre or photography could elicit other connections to nature value perspectives (Galafassi et al. 2018; Muhr 2020).

While our analyses focused on the visioning of the third horizon, an important part of the participatory process was the exploration of transformative change through all three horizons in steps $3-5$. This is a first step in developing pathway scenarios that connect the visions and describe how to get to these more desirable futures (Hamann et al. 2020). The second horizon already offers building blocks for connecting the future visions with the present and outline some specific interventions, but these can be made more concrete and potential conflicts and trade-offs unpacked (Raudsepp-Hearne et al. 2020). An example here is how agriculture inside the national park is both a challenge and an opportunity for achieving desirable nature futures of NPHD. Creating multiple pathways emphasizes that there is no single trajectory and makes explicit different perspectives and trade-offs. It is also possible then to compare and contrast these local scenarios with elements in existing global scenarios, such as the Shared Socioeconomic Pathways, to delineate what alternatives to the dominant global narratives there may be (Aguiar et al. 2020). Similarly, enabled by the thematic analysis (Table 2), these local scenarios may be cross-fertilized with other local NFF-inspired scenarios (e.g. Lembi et al. 2020), and feed into the inductive scenario development process of the IPBES task force on scenarios and models to better inform future assessments (Pereira et al. 2020).

Responding to the remark of one of the participants that "now we need maps and start drawing", a step to extend and concretize the visioning and pathway exploration approach would be to develop spatially explicit scenarios and create maps to visualize the possible futures. Such a step could be facilitated through participatory mapping approaches where stakeholders jointly spatialize their visions (Palacios-Agundez et al. 2015; Reilly et al. 2018). This could serve as a cross-check to determine whether the visions could be realized within the study region. The scenario maps would form the basis for further assessment and quantification of ecosystem services and implications for biodiversity. Easy-to-use, readily available ecosystem services models such as InVEST can be applied for such assessments (Ruckelshaus et al. 2015; Hamel et al. 2021), specifically to analyze implications regarding the Nature for Society perspective of the NFF. From the Nature for Nature and Nature as Culture perspectives the visions and desires of people, as surfaced during our process, challenge conventional modelling approaches, as these fail to represent the known diversity of people-nature interactions (Kok et al. 2016; Rosa et al. 2017). 
National parks and other forms of protected areas are increasingly understood as complex adaptive systems, subject to nonlinearity, uncertainty, emergence and self-organization (Berkes 2004, 2007; Cumming and Allen 2017). From that perspective, the objectives of NPHD will likely evolve over time, and the process of developing the park will never be "finished". Navigating the development trajectory of NPHD towards desirable futures for nature and people can benefit from adaptive co-management approach that includes frequent visioning and pathways exploration as part of a continuous stakeholder engagement process (Olsson et al. 2004; Kerkhoff et al. 2019). As such, the outcomes generated by the workshop process in NPHD should not be seen as final products and could become stepping stones in a series of engagements. Yet, depending on the aims of the process, the scope may be narrowed down further to hold more focused discussions. For example, a follow-up workshop could focus on nature futures of the bulb agriculture within NPHD, to identify more integrated solutions to a known policy challenge. Whatever the context and the aims, it is important to clearly communicate before the workshop to participant stakeholders what will be done with the outcomes. And, in that same vein, to report back to the participants after the workshop what is done with the results.

\section{Conclusion}

This paper presents a novel approach to exploring nature futures that combines a participatory visioning process with an analytical framework. We applied the approach to support the development process of National Park Hollandse Duinen, and designed the approach to test the Nature Futures Framework, a new framework for nature-centered scenario development. We found that the Nature Futures Framework enabled collaborative discovery of diverse perspectives on nature, and, in conjunction with the Three Horizons framework, enabled nature-centered visioning and pathway exploration. The analytical framework exposed the plurality captured in collaboratively created visions of nature futures of National Park Hollandse Duinen and provided insight into the potential contribution to the Agenda 2030. We found that the approach aligned well with the development process of National Park Hollandse Duinen for which it strengthened long-term thinking and plural valuation of nature, which got carried forward in the official landscape strategy for the National Park. While the approach as presented in this paper represents only a first step in the development of more integrated scenarios to inform policy and planning, we see large potential for its application in various contexts to scaffold discussions about the futures we want for nature and people, and how to achieve them.

\section{Literature}

Aguiar APD, Collste D, Harmackova ZV, et al (2020) Co-designing global target-seeking scenarios: A crossscale participatory process for capturing multiple perspectives on pathways to sustainability. Glob Environ Chang 65:. https://doi.org/10.1016/j.gloenvcha.2020.102198

Bai X, van der Leeuw S, O'Brien K, et al (2016) Plausible and desirable futures in the Anthropocene: A new research agenda. Glob Environ Chang 39:351-362. https://doi.org/10.1016/j.gloenvcha.2015.09.017

Bennett EM, Biggs R (Oonsie), Peterson GD, Gordon LJ (2021) Patchwork Earth: navigating pathways to just, thriving, and sustainable futures. One Earth 4:172-176. https://doi.org/10.1016/j.oneear. 2021. 01.004

Berkes F (2004) Rethinking Community-Based Conservation. Conserv Biol 18:621-630. https://doi.org/ $10.1111 / \mathrm{j} .1523-1739.2004 .00077 . \mathrm{x}$ 
Berkes F (2007) Community-based conservation in a globalized world. Proc Natl Acad Sci U S A 104:1518815193. https://doi.org/10.1073/pnas. 0702098104

Bieling C, Eser U, Plieninger T (2020) Towards a better understanding of values in sustainability transformations: ethical perspectives on landscape stewardship. Ecosyst People 16:188-196. https://doi.org/10. $1080 / 26395916.2020 .1786165$

Borrini-Feyerabend G, Dudley N, Jaeger T, et al (2013) Governance of Protected Areas: From understanding to action. Gland, Switzerland: IUCN

Caniglia G, Luederitz C, von Wirth T, et al (2021) A pluralistic and integrated approach to action-oriented knowledge for sustainability. Nat Sustain 4:93-100. https://doi.org/10.1038/s41893-020-00616-z

Chakroun L, Droz L (2020) Sustainability through landscapes: natural parks, satoyama, and permaculture in Japan. Ecosyst People 16:369-383. https://doi .org/10.1080/26395916.2020.1837244

Chan KMA, Balvanera P, Benessaiah K, et al (2016) Why protect nature? Rethinking values and the environment. Proc Natl Acad Sci U S A 113:1462-5. https://doi.org/10.1073/pnas.1525002113

Crutzen PJ (2002) Geology of mankind. Nature 415:23. https://doi.org/10.1038/415023a

Cumming GS, Allen CR (2017) Protected areas as social-ecological systems: perspectives from resilience and social-ecological systems theory. Ecol Appl 27:1709-1717. https://doi.org/10.1002/eap.1584

Cumming GS, Allen CR, Ban NC, et al (2015) Understanding protected area resilience: a multi- scale, social-ecological approach. Ecol Appl 25:299-319. https://doi.org/10.1890/13-2113.1

Curry A, Hodgson A (2008) Seeing in multiple horizons: Connecting futures to strategy. J Futur Stud 13:120 https://jfsdigital.org/wp-content/uploads/2014/01/131-A01.pdf

De Argumentenfabriek (2013) Waardenkaart Natuur. Retreived from https://www.argumentenfabriek. nl/media/1899/12118-waardenkaart-natuur-s.pdf

Díaz S, Settele J, Brondízio ES, et al (2019) Pervasive human-driven decline of life on Earth points to the need for transformative change. Science: 366. https://doi.org/10.1126/science. aax3100

Galafassi D, Tàbara JD, Heras M (2018) Restoring our senses, restoring the Earth. Fostering imaginative capacities through the arts for envisioning climate transformations. Elementa 6:. https://doi.org/10. 1525/elementa. 330

Hamann M, Biggs R, Pereira L, et al (2020) Scenarios of Good Anthropocenes in southern Africa. Futures 118:102526. https://doi.org/10.1016/j.futures.2020.102526

Hamel P, Guerry AD, Polasky S, et al (2021) Mapping the benefits of nature in cities with the InVEST software. npj Urban Sustain 1:. https://doi.org/10.1038/s42949-021-00027-9

Hanspach J, Jamila Haider L, Oteros-Rozas E, et al (2020) Biocultural approaches to sustainability: A systematic review of the scientific literature. People Nat 2:643-659. https://doi .org/10.1002/pan3.10120

Harmáčková Z V., Blättler L, Aguiar APD, et al (2021) Linking multiple values of nature with future impacts: value-based participatory scenario development for sustainable landscape governance. Sustain Sci. https: //doi.org/10.1007/s11625-021-00953-8

Heinrup M, Schultz L (2017) Swedish Biosphere Reserves as Arenas for Implementing the 2030 Agenda. The Swedish Environmental Protection Agency: Report 6742

Hensler L, Merçon J, Vilsmaier U (2021) Diverse values and a common utopia: Insights from a participatory art-based plural valuation experience in Xalapa, Mexico. Case Stud Environ 5:. https://doi.org/10.1525/ cse. 2021.1234747 
Horcea-Milcu AI, Abson DJ, Apetrei CI, et al (2019) Values in transformational sustainability science: four perspectives for change. Sustain Sci 14:1425-1437. https://doi.org/10.1007/s11625-019-00656-1

IPBES (2015) Preliminary guide regarding diverse conceptualization of multiple values of nature and its benefits, including biodiversity and ecosystem functions and services (deliverable 3 (d)). IPBES/4/INF/13

IPBES (2016): The methodological assessment report on scenarios and models of biodiversity and ecosystem services. S. Ferrier, K. N. Ninan, P. Leadley, R. Alkemade, L. A. Acosta, H. R. Akçakaya, L. Brotons, W. W. L. Cheung, V. Christensen, K. A. Harhash, J. Kabubo-Mariara, C. Lundquist, M. Obersteiner, H. M. Pereira, G. Peterson, R. Pichs-Madruga, N. Ravindranath, C. Rondinini and B. A. Wintle (eds.). Secretariat of the Intergovernmental Science-Policy Platform on Biodiversity and Ecosystem Services, Bonn, Germany. 348 pages. https://doi.org/10.5281/zenodo. 3235428

IPBES (2019a) Global assessment report of the Intergovernmental Science-Policy Platform on Biodiversity and Ecosystem Services. E. S. Brondizio, J. Settele, S. Díaz, and H. T. Ngo (editors). IPBES secretariat, Bonn, Germany. 1148 pages. https://doi.org/10.5281/zenodo.3831673

IPBES (2019b) Information on work related to scenarios and models. Report of the Executive Secretary on the implementation of the first work programme for the period 2014-2018. IPBES/7/INF/11

IPBES (2021) Report of the IPBES task force on scenarios and models on its workshop on modelling Nature Futures scenarios under the 2030 IPBES rolling work programme. IPBES/TF/SCN/WSP/2021/1/6

Jacobs S, Zafra-Calvo N, Gonzalez-Jimenez D, et al (2020) Use your power for good: Plural valuation of nature - the Oaxaca statement. Glob Sustain 3:1-7. https://doi.org/10.1017/sus.2020.2

Janssen J (2009a) Sustainable development and protected landscapes: The case of the Netherlands. Int J Sustain Dev World Ecol 16:37-47. https://doi.org/10.1080/13504500902757981

Janssen J (2009b) Protected landscapes in the Netherlands: Changing ideas and approaches. Plan Perspect 24:435-455. https://doi.org/10.1080/02665430903145689

Janssen J, Knippenberg L (2012) From Landscape Preservation to Landscape Governance: European Experiences with Sustainable Development of Protected Landscapes. Stud Environ Appl Geomorphol. https: //doi.org/10.5772/29545

Jiménez-Aceituno A, Peterson GD, Norström A V., et al (2020) Local lens for SDG implementation: lessons from bottom-up approaches in Africa. Sustain Sci 15:729-743. https://doi.org/10.1007/s11625-01900746-0

Kerkhoff L Van, Munera C, Dudley N, et al (2019) Towards future-oriented conservation : Managing protected areas in an era of climate change. Ambio 48:699-713. https://doi.org/10.1007/s13280-018-11210

Kleinschroth F, Kowarik I (2020) COVID-19 crisis demonstrates the urgent need for urban greenspaces. Front Ecol Environ 18:318-319. https://doi.org/10.1002/fee.2230

Kok MTJ, Kok K, Peterson GD, et al (2016) Biodiversity and ecosystem services require IPBES to take novel approach to scenarios. Sustain Sci 12:1-5. https://doi.org/10.1007/s11625-016-0354-8

Lang DJ, Wiek A, Bergmann M, et al (2012) Transdisciplinary research in sustainability science: Practice, principles, and challenges. Sustain Sci 7:25-43. https://doi.org/10.1007/s11625-011-0149-x

Leclere D, Obersteiner M, Barrett M, et al (2020) Bending the curve of terrestrial biodiversity needs an integrated strategy. Nature 585:551-556. https://doi.org/10.1038/s41586-020-2705-y

Lembi RC, Cronemberger C, Picharillo C, et al (2020) Urban expansion in the atlantic forest: Applying the nature futures framework to develop a conceptual model and future scenarios. Biota Neotrop 20:113. https://doi.org/10.1590/1676-0611-bn-2019-0904 
Lum R (2015) Working with Verge. APF compass Methods Analog 5-8

Mace GM (2014) Whose conservation? Science (80- ) 345:1558-1560. https://doi.org/10.1126/science. 1254704

McPhearson T, Iwaniec DM, Bai X (2016) Positive visions for guiding urban transformations toward sustainable futures. Curr Opin Environ Sustain 22:33-40. https://doi .org/10.1016/j. cosust. 2017.04 .004

Merrie A, Keys P, Metian M, Osterblom H (2017) Radical Ocean Futures - scenario development using science fiction prototyping. Futures 0-1.https://doi.org/10.1016/j.futures.2017.09.005

Muhr MM (2020) Beyond words-the potential of arts-based research on human-nature connectedness. Ecosyst People 16:249-257. https://doi.org/10.1080/26395916.2020.1811379

Muradian R, Pascual U (2018) A typology of elementary forms of human-nature relations: a contribution to the valuation debate. Curr Opin Environ Sustain 35:8-14. https://doi.org/10.1016/j.cosust. 2018. 10.014

Nationaal Parken Bureau (2018) De standaard voor de gebiedsaanduiding nationaal park (werkversie mei 2018). Amersfoort

Neefjes J (2018) Landschapsbiografie Nationaal Park Hollandse Duinen: Historisch-landschappelijke karakteristieken en hun ontstaan. Rijksdienst voor het Cultureel Erfgoed (RCE), Amersfoort. ISBN/EAN: 97890-5799-306-0

NPHD (2017) Waar natuur stad en zee verbindt: Onze ambities voor Nationaal Park Hollandse Duinen. Zoetermeer. Retrieved from: https://www.nationaalparkhollandseduinen.nl/wp-content/uploads/ 2019/05/NPHD-ambitiedocument.pdf

NPHD (2020a) Statusaanvraag Nationaal Park Hollandse Duinen: Een Nationaal Park Nieuwe Stijl dat stad en natuur verbindt. Retrieved from: https://www . nationaalparkhollandseduinen.nl/wp-content/ uploads/2020/12/NPHD-Statusaanvraag-2020-LR3.pdf

NPHD (2020b) Uitvoeringsprogramma Nationaal Park Hollandse Duinen 2021-2025. Retrieved from: $\quad$ https://www. nationaalparkhollandseduinen.nl/wp-content/uploads/2020/12/NPHDUitvoeringsprogramma-2020-LR.pdf

Olsson P, Folke C, Berkes F (2004) Adaptive comanagement for building resilience in social-ecological systems. Environ Manage 34:75-90. https://doi.org/10.1007/s00267-003-0101-7

Palacios-Agundez I, Onaindia M, Potschin M, et al (2015) Relevance for decision making of spatially explicit, participatory scenarios for ecosystem services in an area of a high current demand. Environ Sci Policy 54:199209. https://doi.org/10.1016/j.envsci.2015.07.002

Palomo I, Montes C, Martin-Lopez B, et al (2014) Incorporating the social-ecological approach in protected areas in the anthropocene. Bioscience 64:181-191. https://doi.org/10.1093/biosci/bit033

PBL (2020) Report from the workshop "New narratives for nature: operationalizing the IPBES nature futures scenarios." The Hague, Netherlands. 41 pages. Report: 4181

Pereira L, Sitas N, Ravera F, et al (2019) Building capacities for transformative change towards sustainability: Imagination in Intergovernmental Science-Policy Scenario Processes. Elem Sci Anthr 7. https://doi.org/ 10.1525/elementa.374

Pereira LM, Davies KK, Belder E, et al (2020) Developing multiscale and integrative nature-people scenarios using the Nature Futures Framework. People Nat 2:1172-1195. https://doi.org/10.1002/pan3.10146

Pereira LM, Hichert T, Hamann M, et al (2017) Using futures methods to create transformative spaces: visions of a good Anthropocene in Southern Africa. Ecol Soc 23:art19. https://doi.org/10.5751/ES09907-230119 
Rana S, Avila-Garcia D, Dib V, et al (2020) The voices of youth in envisioning positive futures for nature and people. Ecosyst People 16:326-344. https://doi.org/10.1080/26395916.2020.1821095

Raudsepp-Hearne C, Peterson GD, Bennett EM, et al (2020) Seeds of good anthropocenes: developing sustainability scenarios for Northern Europe. Sustain Sci 15:605-617. https://doi.org/10.1007/s11625019-00714-8

Reilly K, Adamowski J, John K (2018) Participatory mapping of ecosystem services to understand stakeholders' perceptions of the future of the Mactaquac Dam , Canada. Ecosyst Serv 30:107-123. https: //doi.org/10.1016/j.ecoser.2018.01.002

Roe M, Townshend T, Davies C, et al (2018) Urban national parks or national park cities? T Ctry Plan 261-267

Rosa IMD, Pereira HM, Ferrier S, et al (2017) Multiscale scenarios for nature futures. Nat Ecol Evol. https : //doi.org/10.1038/s41559-017-0273-9

Ruckelshaus M, McKenzie E, Tallis H, et al (2015) Notes from the field: Lessons learned from using ecosystem service approaches to inform real-world decisions. Ecol Econ 115:11-21. https://doi.org/10.1016/j. ecolecon.2013.07.009

Schultz L, West S, Bourke AJ, et al (2018) Learning to live with social-ecological complexity: An interpretive analysis of learning in 11 UNESCO Biosphere Reserves. Glob Environ Chang 50:75-87. https://doi.org/ $10.1016 / j \cdot g l o e n v c h a .2018 .03 .001$

Secretariat of the Convention on Biological Diversity (2020) Global Biodiversity Outlook 5. Montreal. https : //doi.org/10.5281/zenodo. 4031437

Sharpe B, Fazey I, G, Leicester G, et al (2016) Three Horizons: A powerful practice for transformation. Ecol Soc 21. https://doi.org/10.5751/ES-08388-210247

Steffen W, Broadgate W, Deutsch L, et al (2015) The trajectory of the anthropocene: The great acceleration. Anthr Rev 2:81-98. https://doi.org/10.1177/2053019614564785

Steffen W, Persson A, Deutsch L, et al (2011) The anthropocene: From global change to planetary stewardship. Ambio 40:739-761. https://doi.org/10.1007/s13280-011-0185-x

Turnhout E, Metze T, Wyborn C, et al (2020) The politics of co-production: participation, power, and transformation. Curr Opin Environ Sustain 42:15-21. https://doi.org/10.1016/j.cosust.2019.11.009

UN General Assembly (2012) The future we want. A/RES/66/288

UN General Assembly (2015) Transforming our world: the 2030 Agenda for Sustainable Development. $\mathrm{A} / \mathrm{RES} / 70 / 1$

UNFCCC (2021) Nationally determined contributions under the Paris Agreement. Synthesis report by the secretariat.

Van Heeringen RM, Van der Velde HM (2017) Struinen door de duinen: Synthetiserend onderzoek naar de bewoningsgeschiedenis van het Hollands duingebied op basis van gegevens verzameld in het Malta-tijdperk, Nederlands. Rijksdienst voor het Cultureel Erfgoed, Amersfoort

van Rooij S, Timmermans W, Roosenschoon O, et al (2021) Landscape-based visions as powerful boundary objects in spatial planning: Lessons from three dutch projects. Land 10:1-14. https://doi.org/10.3390/ land10010016

Veenstra A (2020) Landschapsstrategie Nationaal Park Hollandse Duinen. Retrieved from: https://www. nationaalparkhollandseduinen.nl/wp-content/uploads/2020/10/RAPP-Landschapsstrategie-NPHDdef-23sep20-webversie.pdf 
Winkler KJ (2019) The implementation of the conceptual shift in conservation: pathways of three German UNESCO biosphere reserves. Ecosyst People 15:173-180. https ://doi .org/10.1080/26395916. 2019. 1617351

WWF (2020) Living Planet Report 2020 - Bending the curve of biodiversity loss. Almond, R.E.A., Grooten M. and Peterson, T. (Eds). Gland, Switzerland

Wyborn C, Montana J, Kalas N, et al (2021) An agenda for research and action toward diverse and just futures for life on Earth. Conserv Biol 00:1-12. https://doi.org/10.1111/cobi.13671

Zheng X, Wang R, Hoekstra AY, et al (2021) Consideration of culture is vital if we are to achieve the Sustainable Development Goals. One Earth 4:307-319. https ://doi .org/10.1016/j . oneear.2021.01.012

\section{Acknowledgements}

We thank Lisen Schultz, Perrine Hamel and Sven Teurlincx for valuable feedback on the design of the workshop process. We thank Dunea for providing the venue for the workshop process. We thank the participants for their contribution. We appreciate critical feedback on the writing by Andrea Downing, Tim Daw and Caroline Schill.

\section{Disclosure statement}

GL is director of the national park that was the case study area for this study. JJK, GDP, SKV, LMP are part of the IPBES task force that developed the framework that was tested in this study, however this study was not a task force activity. The authors declare that the research was conducted in the absence of any commercial or financial relationships that could be construed as a potential conflict of interest. This work was supported by the Swedish Research Council for Sustainable Development FORMAS under Grant 201802371 and Grant 2019-01648, the Wageningen Institute for Environment and Climate Research (WIMEK) under Grant 5160957732 and the WGS Graduate Programme of Wageningen University \& Research under Grant 5100000470.

\section{Data availability statement}

The data that support the findings of this study are available from the corresponding author, JJK, upon reasonable request.

\section{Appendix A}

Categories of participants

Municipal official (2 different organizations) 2

Provincial official 2

Water authority official (3 different organizations) 4

Government agency official (3 different organizations) 4

Nature management organization employee 2 
Regional collaboration representative (2 different organizations) 2

Sector association representative (2 different organizations) 2

National Park official (2 different organizations) 2

Semi-government company employee 2

Consultancy employee

\section{Appendix B}

Agenda for the workshop (translated from Dutch)

\section{Program interactive workshop about future(s) of National Park Hollandse Duinen}

\section{June $09.00-17.00$ hrs}

Location: XX

The aim of the workshop is to discover with those involved in the Hollandse Duinen National Park the multiplicity of desired relationships between people and nature and to jointly sketch rich visions for the future. In addition, we look for pathways that can contribute to the realization of the visions.

\section{Program}

$9.00-9.30$ hour Arrival and coffee

$9.30-10.45$ hour Introduction of the workshop and each other

* Please bring a photo, or some other form of imagery or object, that depicts why nature is important to you.

10.45 - 12.30 hour Outlining positive futures for people and nature in NPHD using the IPBES 'Nature Futures' framework.

$12.30-13.30$ hour Lunch

13.30 - 15.00 hour $\quad$ Brainstorm the current state and transformative change in NPHD using the '3-Horizons' framework.

15.00 - 15.30 hour Pause

15.30 - 16.30 hour Innovations that can help to achieve the desired perspectives for the future

16.30 - 17.00 hour Plenary feedback and next steps

$17.00-18.00$ hour Drinks

\section{Appendix C}

Example of SDG target coding. The expressions in the example are translated from the original language (Dutch). The anc

The area is a source of renewable energy.

There is sufficient funding for nature management 
All municipalities are effectively working together for the governance of NPHD

Tourism is sustainable

\section{Appendix D}

Table A1. 1st Horizon: What needs to be phased out.

Group /

Spatial planning. Landscape, urban, infrastructure design

Governance, Policy, Regulations

Agriculture and production from land.

Economy, trade and transport.

Biodiversity and management

Livability, health, environment and well-being

Social structure, community participation, behavior, norms, education and awareness
1 - How green is red?

Urban encroaching into the dunes a Fragmented governance. No zoning Pesticide pollution in bulb cultivati Large cargo flows in and out. Most Too little nature protection. Insuffi Population increase (recreation pres 